\title{
Influence of silane content and filler distribution on chemical-mechanical properties of resin composites
}

Tathy Aparecida XAVIER(a) Nivea Regina de Godoy FRÓES-SALGADO(a) Marcia Margarete MEIER ${ }^{(b)}$ Roberto Ruggiero BRAGA(a)

(a) Universidade de São Paulo - USP, School of Dentistry, Department of Biomaterials and Oral Biology, São Paulo, SP, Brazil.

(b) Universidade do Estado de Santa Catarina - UDESC, Chemistry Department, Joinville, SC, Brazil.

Declaration of Interests: The authors certify that they have no commercial or associative interest that represents a conflict of interest in connection with the manuscript.

Corresponding Author:

Tathy Aparecida Xavier

E-mail: tathy@usp.br

DOI: $10.1590 / 1807-3107 B O R-2015 . v o l 29.0072$

Submitted: Jul 31, 2014

Accepted for publication: Feb 18, 2015

Last revision: May 11, 2015

\begin{abstract}
This study investigated the influence of silane concentration and filler size distribution on the chemical-mechanical properties of experimental composites. Experimental composites with silane contents of $0 \%, 1 \%$ and $3 \%$ (in relation to filler mass) and composites with mixtures of barium glass particles (median size $=0.4,1$ and 2 $\mu \mathrm{m})$ and nanometric silica were prepared for silane and filler analyses, respectively. The degree of conversion (DC) was analyzed by FTIR. Biaxial flexural strength (BFS) was tested after 24 -h or 90 -d storage in water, and fracture toughness, after $24 \mathrm{~h}$. The data were subjected to ANOVA and Tukey's test $(\mathrm{p}=0.05)$. The DC was not significantly affected by the silane content or filler distribution. The $0 \%$ silane group had the lowest immediate BFS, and the 90-d storage time reduced the strength of the $0 \%$ and $3 \%$ groups. BFS was not affected by filler distribution, and aging decreased the BFS of all the groups. Silanization increased the fracture toughness of both the $1 \%$ and $3 \%$ groups, similarly. Significantly higher fracture toughness was observed for mixtures with $2 \mu \mathrm{m}$ glass particles. Based on the results, $3 \%$ silane content boosted the initial strength, but was more prone to degradation after water storage. Variations in the filler distribution did not affect BFS, but fracture toughness was significantly improved by increasing the filler size.
\end{abstract}

Keywords: Dental Materials; Dental Restoration, Permanent; Composite Resins; Silanes.

\section{Introduction}

The properties of resin composites can be defined by the characteristics of the organic matrix network,,$^{1,2}$ the reinforcing phase ${ }^{3,4,5,6,7,8,9,10,11}$ and the silane interphase, responsible for chemically bonding the organic and inorganic phases. ${ }^{12,13,14,15,16,17}$

The silane interphase is most commonly composed of the 3-MPTS $(\gamma-3-$ methacryloxypropyltrimethoxysilane) monomer, a bifunctional molecule capable of both polymerizing with the organic resin matrix and establishing a covalent oxane bond (Si-O-Si) with the surface of the filler particles. ${ }^{13,17,18}$ Many studies have researched the influence of the silane interphase on the properties of resin composites; ${ }^{12,13,14,15,16}$ however, the data reported in the literature are very controversial, with some studies indicating no significant differences in the various static mechanical properties ${ }^{14,15,18}$ 
or in the hydrolytic stability ${ }^{18}$ of composites with a wide range of silane concentrations.

The reinforcing phase is a major determinant of the composite mechanical properties, since it affects the stress distribution, may act as a toughening agent, and can also affect light transmission within the composite. ${ }^{3,4,5,6,7,8,11}$ In addition to the volumetric filler fraction and particle shape, aspects such as particle size distribution help define the behavior of the material. ${ }^{4,5,6,7}$ Variations in the particle size may affect the absorption of the energy generated during mechanical loading, and, therefore, influence the mechanical properties of the composite..$^{8,11}$ Nonetheless, there are a small number of studies analyzing the influence of the overall inorganic phase particle size distribution on the chemicalmechanical properties of dental composites, mainly those similar to commercial materials.

Given the importance of controlling the microstructural features of resin composites in order to optimize their properties and durability, and the lack of a consensus on some data, the objectives of this study were: (1) investigate the influence of silane concentration $(0 \%, 1 \%$ or $3 \%$, related to the filler mass) on the chemical-mechanical properties of experimental resin composites and on the susceptibility of these composites to water degradation, and (2) verify the influence of filler particle size distribution on the same properties, and the susceptibility to water degradation of a second series of experimental resin composites. The null hypotheses were: (1) variations in silane concentration do not result in significant differences in the chemical-mechanical properties of experimental resin composites or in their susceptibility to water degradation; and (2) different filler particle size distributions do not influence the same properties and susceptibility to water degradation of experimental resin composites.

\section{Methodology}

\section{Composite preparation}

Two series of experimental composites were prepared (organic and inorganic mass fractions shown in Table 1). The resin matrix of all the materials was composed of BisGMA (bisphenol A diglycidyl dimethacrylate, Evonik Industries, Essen, North Rhine-Westphalia, Germany), TEGDMA (triethylene glycol dimethacrylate, Cognis Performance Chemicals, Southampton, Hampshire, UK), camphorquinone (Esstech, Essington, USA), EDMAB (ethyl-4-dimethylamino benzoate, Sigma-Aldrich, St. Louis, USA) and BHT (butylated hydroxytoluene, Sigma-Aldrich, St. Louis, USA) as an inhibitor. The filler was added to the resin matrix mechanically under vacuum (SpeedMixer, FlackTek, Inc., Landrum, USA).

The first series was used to verify the influence of silane content. It contained barium aluminosilicate and silica particles (median size or $\mathrm{D}_{50}=0.7 \mu \mathrm{m}$ and $40 \mathrm{~nm}$, respectively, Schott AG, Mainz, Germany) and was treated with $\gamma$-3-methacryloxypropyltrimethoxysilane (3-MPTS) (Evonik Industries, Essen, North Rhine - Westphalia, Germany), previously hydrolyzed in ethanolic solution, ${ }^{19}$ at $0 \%$ (control), $1 \%$ or $3 \%$, in relation to the filler mass (Table 1). In order to calculate the number of silane layers around the particles, the specific surface area of each type of particle was measured under nitrogen atmosphere by a surface analyzer (NOVA 1200e, Quantachrome Instruments, Boynton Beach, USA). The method used is based on the Brunauer, Emmett and Teller (BET) theory; it calculates the specific area of the particles according to the cross-sectional area of nitrogen molecules and the number of these molecules used to recover the particles. The following results were obtained: barium glass $0.7 \mu \mathrm{m}=11.7 \mathrm{~m}^{2} / \mathrm{g}$, and silica $40 \mathrm{~nm}=48.3 \mathrm{~m}^{2} / \mathrm{g}$. Thus, considering the area of a 3 -MPTS molecule as $1.11 \times 10^{-18} \mathrm{~m}^{2} / \mathrm{g},{ }^{20}$ and $1 \mathrm{~g}$ of the total filler as composed of $92.9 \%$ barium glass and $7.1 \%$ silica, the approximate number of silane layers around the particles was 1.84 and 5.54 for the $1 \%$ and $3 \%$ silane groups, respectively.

The second series was used to analyze the influence of particle size distribution. It was prepared with four composites consisting of different mixtures of barium glass particles $\left(D_{50}=0.4,1\right.$ or $\left.2 \mu \mathrm{m}\right)$ and nanometric silica $\left(S, D_{50}=40 \mathrm{~nm}\right)$, as presented in Table 1. The fillers were treated with 3\% 3-MPTS. The particle size distribution of the filler mixtures was determined using a diffraction particle size analyzer (Sald-7001, Shimadzu Scientific Instruments, Columbia, USA). 
Table 1. Mass fractions (in weight) of the experimental composites tested (Series 1: silane content; Series 2: particle size distribution).

\begin{tabular}{|c|c|c|c|c|c|c|c|c|c|c|c|c|c|}
\hline \multirow{2}{*}{ Series } & \multirow{2}{*}{ Group* } & \multicolumn{6}{|c|}{ Organic matrix } & \multicolumn{6}{|c|}{ Fillers (median size or $D_{50}$, in $\mu \mathrm{m}$ ) } \\
\hline & & BisGMA & TEGDMA & Camphorquinone & EDMAB & $\mathrm{BHT}$ & Total & $0.04(S)$ & 0.4 & 0.7 & 1 & 2 & Total \\
\hline \multirow[t]{3}{*}{1} & $0 \%$ (control) & 17.4 & 11.6 & 0.15 & 0.3 & 0.05 & 29.5 & 5.0 & - & 65.5 & - & - & 70.5 \\
\hline & $1 \%$ & & & & & & & & & & & & \\
\hline & $3 \%$ & & & & & & & & & & & & \\
\hline \multirow[t]{4}{*}{2} & $0.4-1$ & 11.9 & 7.8 & 0.15 & 0.3 & 0.05 & 20.2 & - & 40.0 & & 40.0 & - & 79.8 \\
\hline & $0.4-1-5$ & & & & & & & 5.0 & 37.5 & & 37.5 & - & \\
\hline & $0.4-1-2$ & & & & & & & - & 26.6 & & 26.6 & 26.6 & \\
\hline & $0.4-1-2-5$ & & & & & & & 5.0 & 25.0 & & 25.0 & 25.0 & \\
\hline
\end{tabular}

* The materials in Series 1 were tested to verify the influence of silane content; the groups contained barium glass and silica particles treated with a previously hydrolyzed 3-MPTS solution at $0 \%$ (control), $1 \%$ or $3 \%$, in relation to the filler mass. The materials in Series 2 were used to verify the influence of filler particle size distribution; the composites were coded into groups according to the median size $\left(D_{50}\right)$ of the barium glass particles used in each formulation $(0.4,1$ or $2 \mu \mathrm{m})$, and the presence of nanometric silica (" $\mathrm{S}$ ", $\left.\mathrm{D}_{50}=40 \mathrm{~nm}\right)$, as follows: 0.4-1, 0.4-1-S, 0.4-1-2, 0.4-1-2-S.

\section{Degree of conversion (DC)}

The composite was inserted into a cylindrical silicone mold (7-mm in diameter, 1-mm thick, $\mathrm{n}=3$ ) and pressed between two glass slides. The spectrum of the non-polymerized material was obtained by Fourier-Transform Near-Infrared (FT-NIR) spectroscopy (Vertex 70, Bruker Optik, Ettlingen, Baden-Württemberg, Germany), between $4000 \mathrm{~cm}^{-1}$ and $10.000 \mathrm{~cm}^{-1}$ (two scans per spectrum, $4 \mathrm{~cm}^{-1}$ resolution). Then, the composite was light-cured (Radii-cal, SDI, Bayswater, Victoria, Australia) under $1,200 \mathrm{~mW} / \mathrm{cm}^{2}$ for $40 \mathrm{~s}$ and stored dry at $37^{\circ} \mathrm{C}$ for $24 \mathrm{~h}$. Afterwards, the spectrum of the polymerized material was obtained, and the DC (in \%) was calculated as the ratio of the transmittance bands located at $6165 \mathrm{~cm}^{-1}$ (vinyl group), obtained with both non-polymerized and polymerized discs.

\section{Biaxial flexural strength (BFS)}

The composite discs (15-mm diameter, 1-mm thick, $\mathrm{n}=10$ ) were light-cured under $1200 \mathrm{~mW} / \mathrm{cm}^{2}$ for $40 \mathrm{~s}$ on each surface, divided into four 10 -s exposures, one per quadrant (Radii-cal, SDI). After 24-h storage in distilled water at $37^{\circ} \mathrm{C}$, the specimens were taken to a "piston on three spheres" device, described in ISO $6872,{ }^{21}$ and positioned in a universal testing machine (model 5565, Instron, Canton, USA) to determine the initial biaxial flexural strength (BFS-initial). Each disc was supported by three $2.5-\mathrm{mm}$ diameter steel spheres positioned $120^{\circ}$ apart on a $10-\mathrm{mm}$ diameter circumference. The load was applied to the center of the composite disc by a flat piston with $1.2 \mathrm{~mm}$ diameter, at a crosshead speed of $0.5 \mathrm{~mm} / \mathrm{min}$. The biaxial flexural strength of the aged specimens was determined after $90-\mathrm{d}$ storage in distilled water at $37^{\circ} \mathrm{C}$ (BFS-90 d).

The BFS (in MPa) for the specimens was calculated using equations 1 to 3 , where $P$ is the failure load (in $\mathrm{N}$ ), $\mathrm{h}$ is the specimen thickness (in $\mathrm{mm}$ ), $\mathrm{v}$ is the composite Poisson's ratio (0.24), $r_{1}$ is the radius of the supporting circumference $(5 \mathrm{~mm}), \mathrm{r}_{2}$ is the radius of the loading area $(0.6 \mathrm{~mm})$, and $r_{3}$ is the radius of the specimen (in $\mathrm{mm}$ ):

$$
\begin{aligned}
& \text { BFS }=[-0.2387 \mathrm{P}(\mathrm{X}-\mathrm{Y})] / \mathrm{h}^{2} \\
& \mathrm{X}=(1+\mathrm{v}) \ln \left(\mathrm{r}_{2} / \mathrm{r}_{3}\right)^{2}+[(1-\mathrm{v}) / 2]\left(\mathrm{r}_{2} / \mathrm{r}_{3}\right)^{2} \\
& \mathrm{Y}=(1+\mathrm{v})\left[1+\ln \left(\mathrm{r}_{1} / \mathrm{r}_{3}\right)^{2}\right]+(1-\mathrm{v})\left(\mathrm{r}_{1} / \mathrm{r}_{3}\right)^{2}
\end{aligned}
$$

After completing the test, fragments of specimens from the 24-h storage group were recovered, and their fractured surfaces were observed under scanning electron microscope (SEM) (15000 kV, LEO 430, LEO Electron Microscopy, Cambridge, England).

\section{Fracture toughness $\left(K_{\mathrm{IC}}\right)$}

Composite fracture toughness was determined by the "single-edge notched beam" method. A stainless steel split mold ( $25 \times 5 \times 2.8 \mathrm{~mm}, \mathrm{n}=15)$ was used to prepare the specimens with a piece of razor blade $(2.8 \times 0.5 \times 2.3 \mathrm{~mm})$ positioned at its center to produce a notch in the specimen. Each surface of the specimen was light-cured for $40 \mathrm{~s}$, with four overlapping 10-s exposures (Radii-cal, SDI). Following the 24-h storage in distilled water $\left(37^{\circ} \mathrm{C}\right)$, the specimens were taken to a universal testing machine (Instron, Canton, MA, USA) and fractured under three-point bending $(0.13 \mathrm{~mm} / \mathrm{min})$. 
Images of the fractured surfaces were digitized under a stereomicroscope at 90x (SZ61, Olympus, Tokyo, Japan). The depth of the notch (a), as well as the width (w) and the thickness (b) of each specimen were measured (Image J software, National Institute of Health, Bethesda, MD, USA). Only the specimens with a/w between 0.45 and 0.50 were used. The $\mathrm{K}_{\mathrm{IC}}$ (in $\mathrm{MPa} \cdot \mathrm{m}^{0.5}$ ) was calculated according to equation 4 , where $\mathrm{P}$ is the failure load (in N) and $\mathrm{S}$ is the span between the supporting rods $(20 \mathrm{~mm})$.

$$
\mathrm{K}_{\mathrm{IC}}=\left[(\mathrm{P} \times \mathrm{S}) /\left(\mathrm{b} \times \mathrm{w}^{1.5}\right)\right] \times \mathrm{f}(\mathrm{a} / \mathrm{w})
$$

The value for $\mathrm{f}(\mathrm{a} / \mathrm{w})$ was calculated according to equation 5 :

$$
\mathrm{f}(\mathrm{a} / \mathrm{w})=(\mathrm{a} / \mathrm{w})^{1 / 3}\{(1.99-(\mathrm{a} / \mathrm{w}) \times[1-(\mathrm{a} / \mathrm{w})] \times[2.15-3.93
$$

$\left.\left.\left.(\mathrm{a} / \mathrm{w})+2.7(\mathrm{a} / \mathrm{w})^{2}\right]\right) /\left(2 \times[1+2(\mathrm{a} / \mathrm{w})] \times[1-(\mathrm{a} / \mathrm{w})]^{3 / 2}\right)\right\}$

\section{Statistical analysis}

Data obtained for the silane content series were subjected to one-way ANOVA, whereas the data set corresponding to the particle size distribution experiments were analyzed by two-way ANOVA (filler size and presence of nanoparticles as main factors). In both instances, the Tukey test was used for multiple comparisons. The influence of aging in water on biaxial flexural strength was analyzed using Student's t-test (BFS-initial versus BFS-90 d). In all tests, $\alpha=0.05$.

\section{Results}

\section{Influence of silane content}

Table 2 shows the results obtained with the different silane contents. DC was not significantly affected by silane content ( $p>0.05$ ). Composites containing fillers treated with $1 \%$ and $3 \%$ silane had a $22 \%$ and $44 \%$ higher BFS-initial, respectively, than the $0 \%$ group $(\mathrm{p}<0.001)$. After $90 \mathrm{~d}$ in water, the control and the composite with $3 \%$ silane presented statistically significant reductions in BFS: $29 \%(p<0.03)$ and $35 \%(p<0.006)$, respectively. The material with $1 \%$ silane content presented a $54 \%$ higher BFS-90d than the control. Silanization increased $\mathrm{K}_{\mathrm{IC}}$ between $28-44 \%$, but no statistically significant difference was observed between the $1 \%$ and $3 \%$ silane content groups $(\mathrm{p}>0.05)$.

Since the fracture surfaces determined by the biaxial flexural test were similar for all the groups, Figure 1 shows the SEM image only for the control group (24-h storage). Sites can be found where the filler particles became detached during fracture propagation, as well as particles covered by the resin matrix.

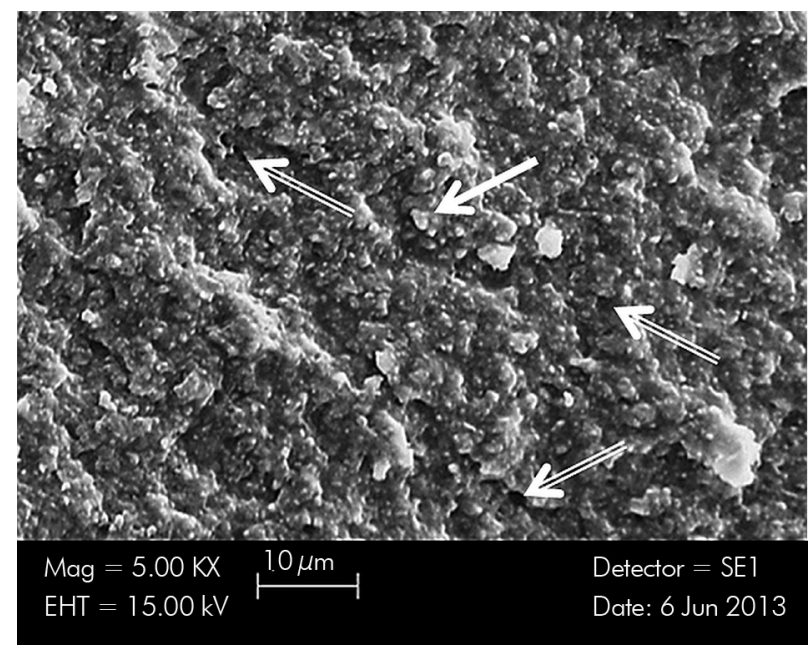

Figure 1. SEM image (5000x) of the fracture surface of the BFS-initial specimen of the control group. Double-trace arrows: sites where particles became detached; single-trace arrow: filler covered by resin matrix.

Table 2. Means and standard deviations for degree of conversion (DC), biaxial flexural strength (BFS, initial and after $90 \mathrm{~d}$ aging in water) and fracture toughness $\left(K_{1 C}\right)$, as a function of silane content. Similar uppercase letters in the same column and lowercase letters in the same line for BFS indicate lack of statistically significant differences among the groups $(p>0.05)$.

\begin{tabular}{lcccc}
\hline Group & DC (\%) & BFS (MPa) & & $\begin{array}{c}K_{1 C} \\
\left(\mathrm{MPa}-\mathrm{m}^{0.5}\right)\end{array}$ \\
\hline $0 \%$ & $78.3(0.8)^{\mathrm{A}}$ & $77.9(11.4)^{\mathrm{C}, \mathrm{a}}$ & $60.5(19.5)^{\mathrm{B}, \mathrm{b}}$ & $0.85(0.13)^{\mathrm{B}}$ \\
$1 \%$ & $77.4(3.3)^{\mathrm{A}}$ & $95.2(9.3)^{\mathrm{B}, \mathrm{a}}$ & $93.0(24.5)^{\mathrm{A}, \mathrm{a}}$ & $1.09(0.15)^{\mathrm{A}}$ \\
$3 \%$ & $77.8(4.0)^{\mathrm{A}}$ & $112.5(19.2)^{\mathrm{A}, \mathrm{a}}$ & $83.5(20.8)^{\mathrm{A}, \mathrm{B}, \mathrm{b}}$ & $1.22(0.24)^{\mathrm{A}}$ \\
\hline
\end{tabular}




\section{Influence of particle size distribution of filler load}

Figure 2 shows the particle size distribution of the fillers used in each of the four tested composites. The values for $\mathrm{D}_{25}, \mathrm{D}_{50}$ (median), $\mathrm{D}_{75}$, mean, mode and amplitude (minimum - maximum values) for each filler mixture are shown in Table 3.

A distinguishable feature among filler mixtures is the presence of a well-defined peak at approximately $1.63 \mu \mathrm{m}$ (Figure 2) for mixtures containing 2- $\mu \mathrm{m}$ particles. The presence of $5 \%$ silica nanoparticles decreased the particle size parameters for the mixtures containing 0.4 and $1 \mu \mathrm{m}$ particles. On the other hand, the effect of these nanoparticles in the mixtures containing $2 \mu \mathrm{m}$ particles was negligible.

Table 4 shows the test results for the composites with different filler distributions. Degree of conversion and biaxial strength (both initial and after aging) were not affected by filler size or the presence of silica nanoparticles $(p>0.05)$. The $90-d$ storage in water decreased the strength by $23-25 \%$ for all experimental composites ( $p<0.035)$. A small, but statistically significant higher composite fracture toughness was observed with the addition of fillers with $\mathrm{D}_{50}=2 \mu \mathrm{m}(\mathrm{p}<0.05)$, regardless of the presence of silica nanoparticles.

Figure 3 shows the SEM image of the fractured surface of the BFS-initial specimen of the 0.4-1 group. Holes left by detached particles can be observed, as well as particles covered by the resin matrix.

\section{Discussion}

The first null hypothesis was partially rejected. Although one end of the 3-MPTS molecule copolymerizes with the resin matrix, the addition of $1 \%$ and $3 \%$ silane to the fillers did not significantly
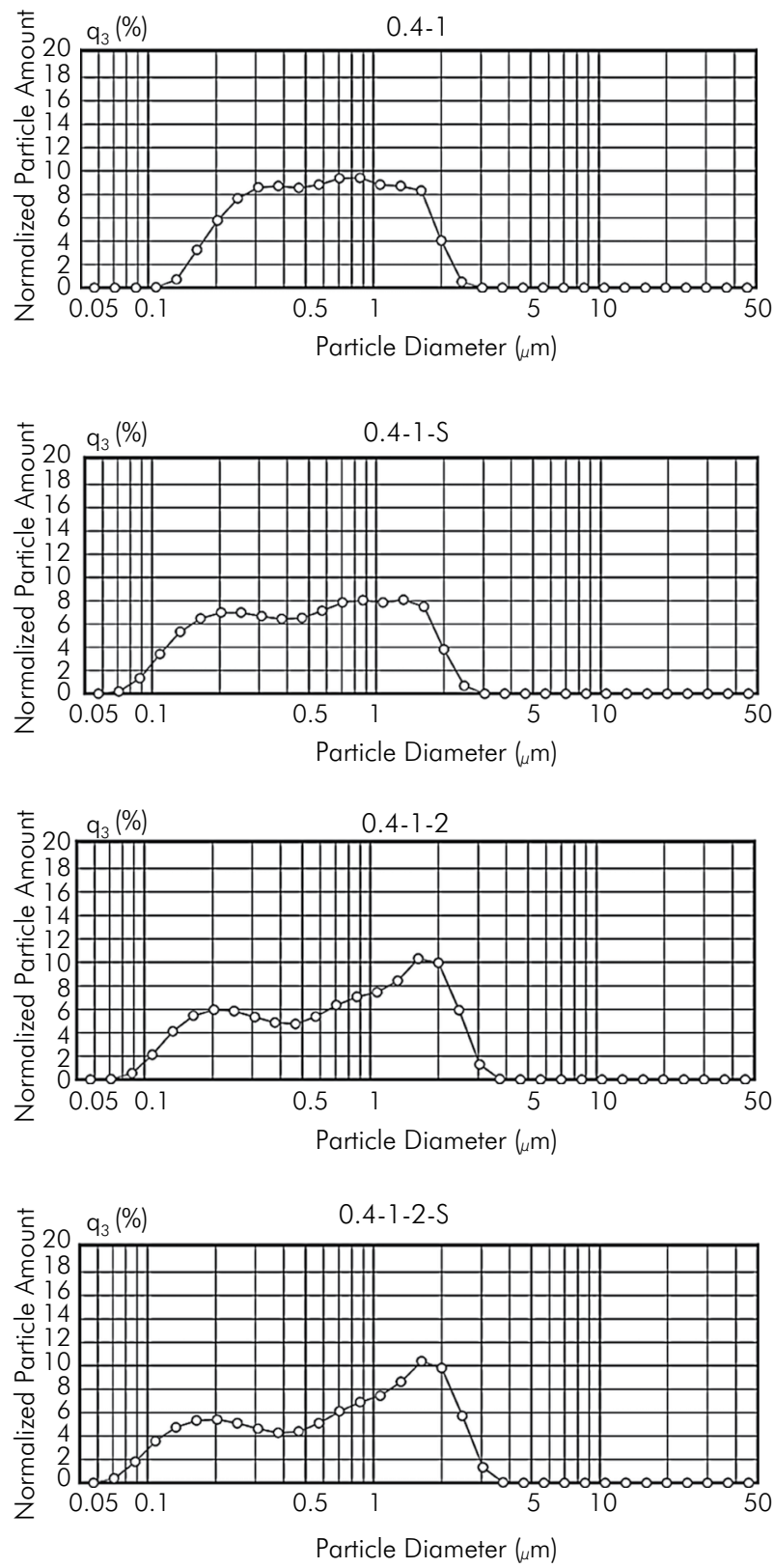

Figure 2. Particle size distribution (frequency versus diameter, in $\mu \mathrm{m}$ ) of the filler mixtures.

Table 3. Characterization of particle size distribution* for the different filler mixtures.

\begin{tabular}{lcccccc}
\hline Group & $D_{25}(\mu \mathrm{m})$ & $\mathrm{D}_{50}$ or Median $(\mu \mathrm{m})$ & $\mathrm{D}_{75}(\mu \mathrm{m})$ & Mean $(\mu \mathrm{m})$ & Mode $(\mu \mathrm{m})$ & Amplitude $(\mu \mathrm{m})$ \\
\hline $0.4-1$ & 0.34 & 0.62 & 1.09 & 0.60 & 0.87 & $0.12-3.37$ \\
$0.4-1-S$ & 0.24 & 0.52 & 1.04 & 0.49 & 1.32 & $0.06-3.37$ \\
$0.4-1-2$ & 0.29 & 0.78 & 1.53 & 0.67 & 1.63 & $0.06-4.15$ \\
$0.4-1-2-S$ & 0.27 & 0.78 & 1.53 & 0.64 & 1.63 & $0.06-4.15$ \\
\hline
\end{tabular}

* The amplitude intervals are approximate because the laser diffraction method provides arbitrary standardized frequencies of values. 
Table 4. Means and standard deviations for degree of conversion (DC), biaxial flexural strength (BFS, initial and after $90 \mathrm{~d}$ aging in water) and fracture toughness (KIC) as a function of barium filler sizes (in $\mu \mathrm{m}$ ), and the presence of silica nanoparticles (S). Similar uppercase letters in a given column and lowercase letters in the same line indicate lack of statistical difference for BFS ( $p>0.05)$.

\begin{tabular}{|c|c|c|c|c|}
\hline \multirow{2}{*}{ Filler mixture } & \multirow{2}{*}{ DC (\%) } & \multicolumn{2}{|c|}{ BFS (MPa) } & \multirow{2}{*}{$\begin{array}{c}\mathrm{K}_{\mathrm{IC}} \\
\left(\mathrm{MPa}-\mathrm{m}^{0.5}\right)\end{array}$} \\
\hline & & initial & $90 d$ & \\
\hline $0.4-1$ & $75.2(1.2)^{\mathrm{A}}$ & $118.3(16.1)^{A, a}$ & $89.8(11.4)^{A, b}$ & $1.17(0.16)$ \\
\hline 0.4-1-S & $76.1(0.9)^{A}$ & $126.0(18.6)^{A, a}$ & $94.2(10.1)^{A, b}$ & $1.18(0.06)$ \\
\hline $0.4-1-2$ & $77.7(1.9)^{A}$ & $118.8(18.3)^{A, a}$ & $91.8(11.6)^{A, b}$ & $1.25(0.10)^{*}$ \\
\hline $0.4-1-2-5$ & $76.3(2.9)^{\mathrm{A}}$ & $116.2(32.7)^{A, a}$ & $89.0(10.4)^{A, b}$ & $1.29(0.14)^{*}$ \\
\hline
\end{tabular}

* Only filler size caused a significant difference in fracture toughness; therefore, the composite containing the 0.4-1-2 $\mu \mathrm{m}$ mixture presented a higher $\mathrm{K}_{\mathrm{IC}}$ than the composite containing 0.4-1 $\mu \mathrm{m}$, regardless of the presence of nanoparticles.

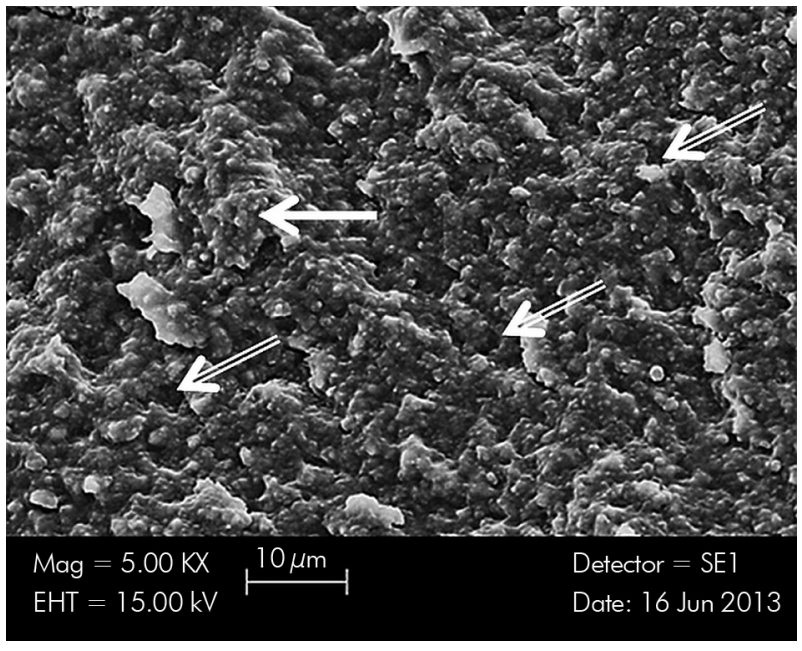

Figure 3. SEM image (5000x) of the fracture surface of the BFS-initial specimen of the 0.4-1 group. Double-trace arrows: sites where particles became detached; single-trace arrow: filler covered by resin matrix.

affect the DC, in agreement with the existing literature. ${ }^{15}$ This means that the number of vinyl groups from 3-MPTS incorporated into the matrix network is relatively small in relation to the number of carbon double bonds from the matrix monomers. Only silane contents as high as $10 \%$ have been found to reduce DC by early gelation from the high density of polymerizable vinyl groups around the filler particles. ${ }^{22}$ The similar DC shown by the three composites indicates that the differences in mechanical properties stemmed from the characteristics of the interphase, and not from the differences in the polymer matrix.

The other end of the 3-MPTS can establish oxane bonds with the hydroxyl groups on the surface of the filler, ${ }^{13}$ improving the stress distribution between both phases. ${ }^{9}$ In the absence of silanization, polymer chains interact with the filler surface by means of secondary bonds, which are much less stable and weaker than the oxane bonds. The inferior BFS of the $0 \%$ silane group was already expected, based on previous studies. ${ }^{12,14,16}$ Moreover, the lower resistance of this group to crack propagation was verified by the lower $\mathrm{K}_{\mathrm{IC}}$.

The higher BFS-initial of the $3 \%$ versus the $1 \%$ silane composite suggests more effective functionalization. After prolonged storage, both $1 \%$ and 3\% silane contents resulted in similar BFS, evidencing that reinforcement is lost by interphase degradation. ${ }^{16}$ Because 3-MPTS has three methoxy groups $\left(-\mathrm{OCH}_{3}\right)$, it may establish oxane bonds not only with the filler surface, but also with other silane molecules (the same Si-O-Si [siloxane] bonds). Because of the strong ionic characteristics of Si-O-Si bonds, they are more susceptible to hydrolytic degradation than the covalent bonds formed between silane and the organic matrix. Among other types of secondary bonds, unreacted silanol groups (not forming $\mathrm{Si}-\mathrm{O}-\mathrm{Si}$ ) may form hydrogen bonds with other silane molecules and with the surface of glass particles (physisorbed silane). The amount of physisorbed silane is proportional to the concentration of the silane in the solution, since multiple layers consisting of many physisorbed molecules form around the filler at high silane levels. This physisorbed silane can be desorbed more easily than Si-O-Si bonds in the presence of water, which competes for the hydrophilic binding sites in the filler surface and in the chemisorbed silane molecules. ${ }^{13,17,18}$ The number of silane layers around the particles was approximately 1.8 and 5.5 for the $1 \%$ and 3\% silane groups, respectively. Therefore, the statistically significant reduction in strength presented by the 3\% 
group, plus the fact that only the $1 \%$ group showed higher BFS than the $0 \%$ group after $90 \mathrm{~d}$, evidences the occurrence of hydrolytic degradation within the relatively thicker interphase of the 3\% group.

In respect to Series 2, nanoparticles were intentionally combined with barium glass of small median values $\left(D_{50}\right)$ in this study, in an attempt to reproduce the filler formulations found in commercial composites classified as "microhybrid" or "nanohybrid." Although the filler mixtures were not very different in terms of amplitude, they presented different average, median $\left(\mathrm{D}_{50}\right)$ and mode values. The different filler mixtures did not result in a normal, Gaussian filler distribution. Furthermore, the average or the $\mathrm{D}_{50}$ (median) - as different manufacturers refer to the filler size - do not describe the particle size distribution of their composites adequately.

The second null hypothesis was partially rejected. Since the refraction index of the filler particles is not the same as that of the organic matrix, the filler particles tend to contribute to dispersion of the light at the matrix/filler interface during photoactivation. Furthermore, since particle size is one of the main factors influencing dispersion of light (some sizes interfere with the dispersion of specific light wave lengths), ${ }^{23,24,25,26,27}$ DC could be affected by the particle size distribution of the filler. However, in agreement with a previous study, ${ }^{4}$ DC was not affected by the tested filler distribution. This indicates that when differences in mechanical properties are detected, they can be ascribed to the different filler distributions. Although an increase in strength is expected with smaller particles, ${ }^{5,28}$ the differences in filler distributions in the present study were not large enough to affect BFS. The fracture strength of predominantly elastic materials is determined by their flaw population. This could also explain the similar strengths among the tested composites. Likewise, the susceptibility to water degradation was not affected by filler distribution, or the presence of silica nanoparticles, insofar as all the composites showed a similar decrease in strength after $90 \mathrm{~d}$. All fillers were treated with the same amount of silane (i.e., $3 \%$ of the particle weight). This may have resulted in a thicker interphase, more susceptible to hydrolysis, as discussed in the previous topic.

As tested, fracture toughness proved to be more sensitive than BFS to filler distribution. Composites with mixtures containing fillers with $\mathrm{D}_{50}=2 \mu \mathrm{m}$ presented statistically higher $\mathrm{K}_{\mathrm{IC}}$, regardless of the presence of $5 \mathrm{wt} \%$ of silica nanoparticles. The proneness toward higher fracture toughness in composites with larger particles has been identified in previous studies. ${ }^{11,29,30}$ Filler particles dispersed in the resin matrix may act as toughening agents either by causing deflection of the crack, when the crack path is forced to change its direction (with an associated reduction in stress intensity) in order to continue its propagation through the lower resistance polymer matrix, or by crack bridging, when the particles prevent opening of the crack wave. ${ }^{8,9,10,11}$ The larger particles in these groups could have contributed to improving both toughening mechanisms, thus reducing the stress intensity at the crack tip and preventing its unstable growth.

\section{Conclusion}

The higher (3\%) silane content had a beneficial effect on the initial biaxial strength, but seemed to be more prone to the deleterious effects of prolonged water storage. Fracture toughness increased with silanization, regardless of the silane concentration. The small variations in filler sizes within the total relatively narrow range did not affect BFS, either initially or after water storage. Fracture toughness, on the other hand, improved significantly with small increases in filler size.

\section{Acknowledgments}

The authors would like to thank FGM Produtos Odontológicos (Joinville, Brazil) for preparing the experimental composites, Mr. Antonio Carlos Lascala, for his technical support, and Coordenação de Aperfeiçoamento de Pessoal de Nível Superior - CAPES (Coordination for the Enhancement of Higher Education Personnel), for its financial support (PNPD-CAPES 02436/09-4). 


\section{References}

1. Gajewski VE, Pfeifer CS, Froes-Salgado NR, Boaro LC, Braga RR. Monomers used in resin composites: degree of conversion, mechanical properties and water sorption/ solubility. Braz Dent J. 2012;23(5):508-14

2. Lemon MT, Jones MS, Stansbury JW. Hydrogen bonding interactions in methacrylate monomers and polymers. J Biomed Mater Res A. 2007;83(3):734-46.

3. Klapdohr S, Moszner N. New inorganic components for dental filling composites. Monatsh Chem. 2005;136(1):21-45.

4. Ornaghi BP, Meier MM, Rosa V, Cesar PF, Lohbauer U, Braga RR. Subcritical crack growth and in vitro lifetime prediction of resin composites with different filler distributions. Dent Mater. 2012;28(9):985-95.

5. Beun S, Glorieux T, Devaux J, Vreven J, Leloup G. Characterization of nanofilled compared to universal and microfilled composites. Dent Mater. 2007;23(1):51-9.

6. Ilie N, Rencz A, Hickel R. Investigations towards nano-hybrid resin-based composites. Clin Oral Investig. 2013;17(1):185-93.

7. Fujita K, Ikemi T, Nishiyama N. Effects of particle size of silica filler on polymerization conversion in a light-curing resin composite. Dent Mater. 2011;27(11):1079-85.

8. Cesar PF, Rosa V, Pinto MM, Yoshimura HN, Xu LR. Effect of ion exchange on R-curve behavior of a dental porcelain. J Mater Sci. 2011;46(1):117-22.

9. Shah MB, Ferracane JL, Kruzic JJ. R-curve behavior and toughening mechanisms of resin-based dental composites: effects of hydration and post-cure heat treatment. Dent Mater. 2009;25(6):760-70.

10. Shah MB, Ferracane JL, Kruzic JJ. Mechanistic aspects of fatigue crack growth behavior in resin based dental restorative composites. Dent Mater. 2009;25(7):909-16.

11. Shah MB, Ferracane JL, Kruzic JJ. R-curve behavior and micromechanisms of fracture in resin based dental restorative composites. J Mech Behav Biomed Mater. 2009;2(5):502-11.

12. Bowen RL. Properties of a silica-reinforced polymer for dental restorations. J Am Dent Assoc. 1963;66:57-64.

13. Akovali G, Ishida H, editors. The Interfacial Interactions in Polymeric Composites. Netherlands: Springer Netherlands; 1993. Controlled interphases in glass-fiber and particulate reinforced polymers - structure of silane coupling agents in solutions and on substrates; p. 169-99. (NATO ASI Series; vol. 230).

14. Karmaker A, Prasad A, Sarkar NK. Characterization of adsorbed silane on fillers used in dental composite restoratives and its effect on composite properties. J Mater Sci Mater Med. 2007;18(6):1157-62.

15. Sideridou ID, Karabela MM. Effect of the amount of 3-methacyloxy propyltrimethoxysilane coupling agent on physical properties of dental resin nanocomposites. Dent Mater. 2009;25(11):1315-24.
16. Ikejima I, Nomoto R, McCabe JF. Shear punch strength and flexural strength of model composites with varying filler volume fraction, particle size and silanation. Dent Mater. 2003;19(3):206-11.

17. Antonucci JM, Dickens SH, Fowler BO, Xu HHK, McDonough WG. Chemistry of silanes: Interfaces in dental polymers and composites. J Res Natl Inst Stand Technol. 2005;110(5):541-58.

18. Arksornnukit M, Takahashi H, Nishiyama N. Effects of silane coupling agent amount on mechanical properties and hydrolytic durability of composite resin after hot water storage. Dent Mater J. 2004;23(1):31-6.

19. Hooshmand T, Matinlinna JP, Keshvad A, Eskandarion S, Zamani F. Bond strength of a dental leucite-based glass ceramic to a resin cement using different silane coupling agents. J Mech Behav Biomed Mater. 2013;17:327-32.

20. Soderholm KJ, Shang SW. Molecular orientation of silane at the surface of colloidal silica. J Dent Res. 1993;72(6):1050-4.

21. International Organization for Standardization. ISO 6872. Dentistry - dental ceramics. Geneva: International Organization for Standardization; 1999.

22. Wilson KS, Zhang K, Antonucci JM. Systematic variation of interfacial phase reactivity in dental nanocomposites. Biomaterials. 2005;26(25):5095-103.

23. Santos GB, Alto RV, Filho HR, Silva EM, Fellows CE. Light transmission on dental resin composites. Dent Mater. 2008;24(5):571-6.

24. Arikawa H, Fujii K, Kanie T, Inoue K. Light transmittance characteristics of light-cured composite resins. Dent Mater. 1998;14(6):405-11.

25. Emami N, Sjodahl M, Soderholm KJ. How filler properties, filler fraction, sample thickness and light source affect light attenuation in particulate filled resin composites. Dent Mater. 2005;21(8):721-30.

26. Masotti AS, Onofrio AB, Conceicao EN, Spohr AM. UVvis spectrophotometric direct transmittance analysis of composite resins. Dent Mater. 2007;23(6):724-30.

27. Mitra SB, Wu D, Holmes BN. An application of nanotechnology in advanced dental materials. J Am Dent Assoc. 2003;134(10):1382-90.

28. Kalliyana Krishnan V, Yamuna V. Effect of initiator concentration, exposure time and particle size of the filler upon the mechanical properties of a light-curing radiopaque dental composite. J Oral Rehabil. 1998;25(10):747-51.

29. Kim KH, Okuno O. Microfracture behaviour of composite resins containing irregular-shaped fillers. J Oral Rehabil. 2002;29(12):1153-9.

30. Becher PF, Sun EY, Plucknett KP, Alexander KB, Hsueh CH, Lin HT, et al. Microstructural design of silicon nitride with improved fracture toughness: I, effects of grain shape and size. J Am Ceram Soc. 1998;81(11):2821-30. 